\title{
A CSRR Loaded Patch Antenna for Cognitive Radio Application
}

\author{
S. Venkatesh, M. Karthick, K. Supriya, A. P. Jayamurugaraja \\ Department of Electronics and Communication Engineering, Dhirajlal Gandhi College of Technology, Salem, \\ India \\ Email: venkatesh.ece@dgct.ac.in, karthick.ece@dgct.ac.in, supriya.ece@dgct.ac.in, \\ jayamurugarajaap.ece@dgct.ac.in
}

Received 5 April 2016; accepted 25 April 2016; published 14 June 2016

Copyright (C) 2016 by authors and Scientific Research Publishing Inc.

This work is licensed under the Creative Commons Attribution International License (CC BY). http://creativecommons.org/licenses/by/4.0/

(c) (i)

Open Access

\section{Abstract}

In this paper, an electromagnetic metamaterial patch antenna is designed and simulated for cognitive radio applications, as cognitive radio communication is anticipated to be a new technology which utilizes all the bands of radio spectrum. This work uses a complementary split ring resonator between the patch and the ground plane for the purpose of size miniaturization. The proposed antenna system is capable of operating in the frequency range of about 2 to $5 \mathrm{GHz}$. This wide-band design makes it viable for wide spectrum with 80 percentage effective frequency being covered in the designed band. The desired patch antenna has been simulated using Advanced System Design (ADS) simulator. The simulated results are proved to be good in agreement with cognitive radio application.

\section{Keywords}

Complementary Split Ring Resonator, Cognitive Radio, Metamaterial, Miniaturization, Microstrip Antenna

\section{Introduction}

The new methodology paved the way for wireless communication which overcomes certain drawbacks in wired communication such as high cost, data loss, ineffective long distance communication and limited user access. The electromagnetic spectrum is found to be limited natural resource and getting congested due to increasing demand by users for wireless applications which leads to delay, reduced speed and data collision. The recent survey of International Telecommunication Union (ITU) states that $90 \%$ of licensed spectrum remains unused. In 2002, Federal Communication Commission (FCC) also stated 70\% of licensed spectrum is underutilized [1]. 
Therefore cognitive radio is envisioned as the possible solution for utilizing the entire frequency spectrum from the available licensed bands. The challenge of finding out unused spectrum within available bandwidth is huge. In this scenario, the cognitive radio itself identifies the unused spectrum range from licensed spectrum. To improve the spectral utilization dynamically cognitive radio is provided with specific platform called as Software Defined Radio (SDR). The general architecture of cognitive radio includes two antennas. They are wideband antennas and reconfigurable narrowband antenna [2]. Where the purpose of wideband antenna is used to sense the wireless medium continuously and parallel searches the unused spectrum whereas the reconfigurable narrowband modifies the resonant frequency dynamically [3]. Also the combination of both wide-narrowband reconfigurable antennas can be used for spectrum sensing and data communication purpose. But, it is hard to keep sufficient isolation between the spectrum sensing and data communication. Therefore, the two different antennas are used for quick accessibility in limited space. This unique difference creates the big challenge for antenna designers for cognitive radio application. The SDR applications needs a wideband antenna which is dynamically acts as a transceiver for multiple frequency bands. So these types of antennas are found to be low in size, cost and weight [4].

In recent years, all communication application needs compact, low cost antennas in both military and commercial applications. A low profile and low volume antenna called microstrip antenna may be used for all the above mentioned applications. The microstrip antenna is also known as patch or printed antenna which is easily fabricated by using principles of printed circuit boards. But the major challenging issue for antenna designer in microstrip patch antenna is size miniaturization [4]. A new engineering design based on artificial materials which is not yet to be found in nature is called as metamaterial. The significance of metamaterial proves to be the material with negative refractive index. Some of the miniaturization techniques are based on shorting plates or shorting pins, fractalizing the radiating edges which are not based on artificial materials. The types of conventional metamaterial based miniaturization techniques are High Impedance Surface (HIS), Reactive Impedance Surface (RIS), Split Ring Resonator (SRR) and Complementary Split Ring Resonator (CSRR). This provides straight way to achieve high level of miniaturization. The major drawback of HIS and RIS is that it requires high permittivity (dielectric constant) and thick substrates. But it leads to inexpensive fabrication of antenna. The above requirement can be achieved through the use of split ring resonator, since it requires very thick substrates for the meaningful size reduction. By etching arrays of Split Ring Resonator (SRR) into the ground plane leads to possible size reduction which is called complementary split ring resonator [5]-[7].

This paper designs an antenna that operates in multiple frequency, which is designed for cognitive radio application. A metamaterial inspired patch antenna is designed on wideband patch antenna. The proposed antenna design has complementary split ring resonator (CSRR), dielectric substrate and ground plane. The operating range of the proposed design is from $2 \mathrm{GHz}$ to $5 \mathrm{GHz}$ band. The total size of the antenna is $44 \times 91 \times 1.574 \mathrm{~mm}$. $80 \%$ frequency coverage is achieved from the proposed wideband antenna design. The placement of CSRR leads possible reduction in the size of the antenna. Here the results of return loss are obtained on the basis of with and without ground plane of the antenna. Antenna concerned parameters are obtained and discussed: Return loss, radiation pattern, Gain, Directivity, Efficiency and radiated power. Two circular ring type CSRR is used at backside of the patch antenna design. The return loss shows that the antenna deliberates better performance for the designed frequency range. In the other works, the design is concentrated on only one resonance frequency and here the proposed work gives the complete good results for the band of $2 \mathrm{GHz}$ to $5 \mathrm{GHz}$ in wideband antenna design. This paper organized as follows: Section 2 details about the cognitive radio, Section 3 provides microstrip antenna and metamaterial, Section 4 provides the antenna design and configuration, Section 5 gives the complete results and discussion of the antenna parameters and the paper is concluded in Section 6.

\section{Cognitive Radio}

The increasing demand in wireless communication and connectivity leads to effective utilization of licensed and unlicensed frequency spectrum. In current scenario, the radio spectrum is insufficient for the user demand. A new design methodology exploits the drawbacks of existing spectrum in effective way is called Cognitive Radio (CR). Figure 1 illustrates the diversity qualities of CR. It provides efficient utilization of available both licensed and unlicensed radio spectrum for enhancing the performance of the radio communication systems [8].

CR is an intelligent system with ability to learn from its environment and can adapt to its required parameters. It can perform an effective utilization of radio spectrum for reliable communication. Learning is one of the important considerations for designing the cognitive communication system. Learning is possible through the spectrum 
sensing on wide range of frequency bands by integrating all the collected information using soft parameters [9]. For decision making, it needs both hard (spectrum sensing) and soft parameters. The CR allows unlicensed users (secondary users) to use spectrum bands with licensed users (primary users) [10].

There are basically two approaches for utilizing the available bandwidths. The underlay and overlay model, shown in Figure 2 and Figure 3 respectively, illustrate how two users can utilize the frequency bands without interfering each other. It needs the diversity quality spectrum sensing, spectrum decision, spectrum sharing and spectrum mobility.

\section{Microstrip Antenna and Metamaterial}

In the past decade, the low profile antenna was on huge demand from commercial applications to military due to its characteristics such as cost, size, weight, ease of installation and performance. The need for the antennas is extended to government controlled bandwidths and other commercial applications like mobile and wireless

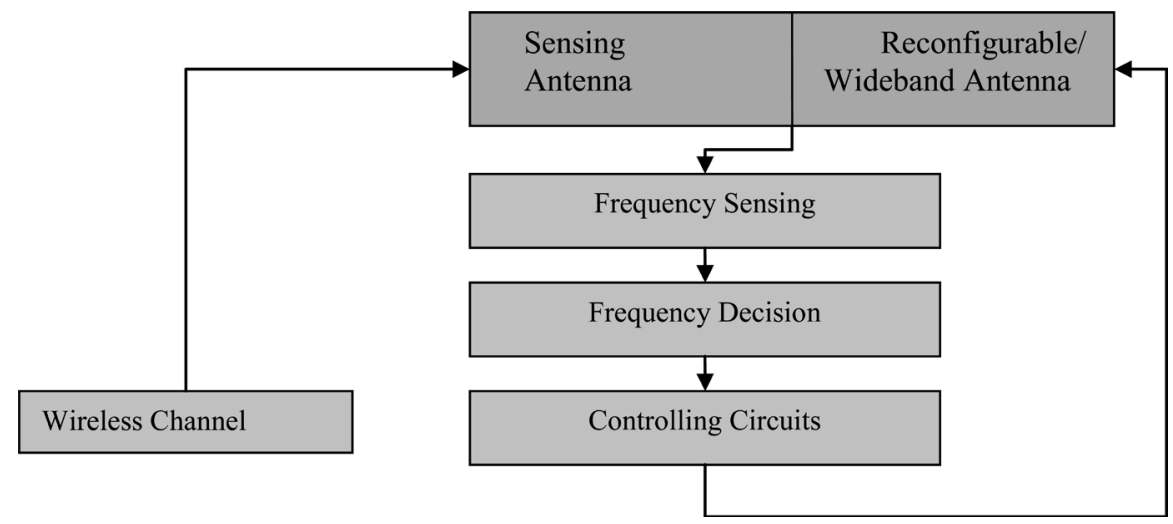

Figure 1. Diversity qualities of cognitive radio with flow model.

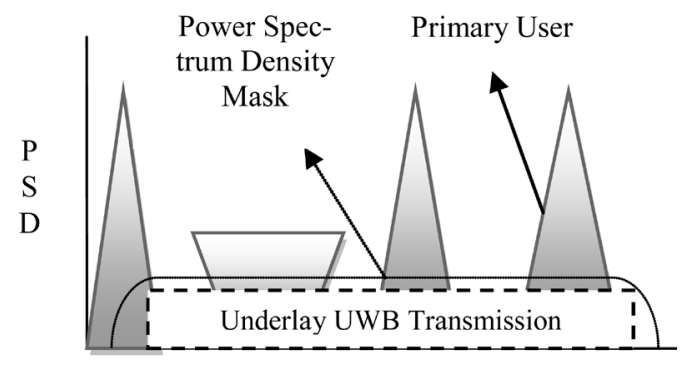

PSD-Power Spectral Density

Frequency

Figure 2. Underlay model with UWB transmission.

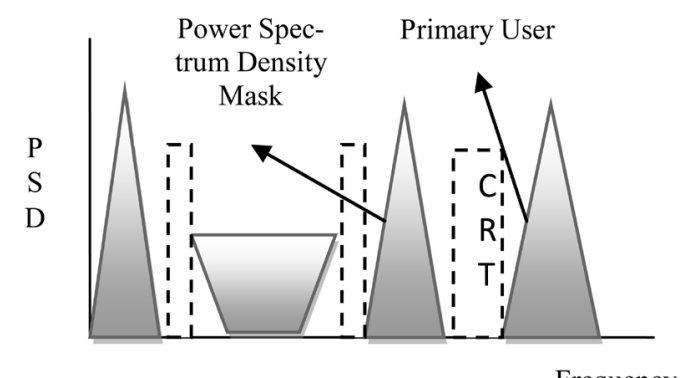

PSD-Power Spectral Density

Frequency

CRT-Cognitive Radio Transmission

Figure 3. Overlay model with cognitive radio transmission. 
applications. Microstrip antennas meet the above requirements. These antennas, called patch or printed types, are mostly inexpensive to manufacture through the use of printed circuit technologies. It consists of metallic patch mounted on a larger metal sheet is called ground plane [11]. Microstrip antenna contains four elements, ground plane, dielectric substrate, patch and a feed which supplies the RF power. The patch shape may be either linear or non-linear, based on the applications it may vary. Some of the regular shapes are elliptical, circular, square and rectangular. One such rectangular shape is shown in Figure 4. Four types of feeding mechanisms are, microstrip line feed, coaxial feed, aperture coupled feed and proximity coupled feed. A simple feed is microstrip-line feed because, ease of fabrication and matching. The main feature of coaxial feed is its low spurious radiation. The above two mechanisms are commonly used for all type of applications [12].

Metamaterial is an artificial material which cannot be seen in nature. Metals or plastics with repeating patterns are important source of the metamaterial. The primary property of this material is that it reverse the refractive index, which is called negative index metamaterial. Recently, the size miniaturization has become one of the important key factors for designing any antenna system. Some of the conventional techniques may be shorting pins or shorting plates and fractalizing the radiating edge. The Split Ring Resonator (SRR) and Complementary Split Ring Resonator (CSRR) are artificial material based miniaturization techniques [6]. The CSRR is a popular and better method. Figure 5 shows the proposed size miniaturization geometry. And the radius of the CSRR is about $6 \mathrm{~mm}$.

\section{Design and Configuration}

Antenna design and simulation analysis are carried out through Advanced Design System (ADS) software. RF, Patch antenna and high speed digital designs are possible in this software.

\subsection{Antenna Design}

The proposed antenna design is expected to operate between the frequencies of about $2 \mathrm{GHz}$ to $5 \mathrm{GHz}$. These frequencies are used for cognitive radio applications. Figure 5(a) shows the proposed wideband patch antenna geometry with simple feed. Here E-shape patch geometry has been selected to achieve wideband characteristics. It has advantages of single layer with single feed structure. Simple microstrip-line feed is used to supply the RF power. A single layer structure has been proposed with the substrate of Rogers/RT Duroid 5880 having the dielectric constant of about 2.2 and thickness is $1.574 \mathrm{~mm}$. The choice of substrate depends on dielectric constant (Permittivity), Loss tangent, Conductivity and cost. The selected substrate has low dielectric constant, loss tangent and thickness. The proposed wideband antenna occupies the volume of $44 \times 91 \times 1.574 \mathrm{~mm}$ with the ground plane of about $85 \times 130 \mathrm{~mm}$. The antenna geometry key dimensions are given in Table 1 . The dimensions of the proposed antenna are optimized to operate between $2 \mathrm{GHz}$ to $5 \mathrm{GHz}$ band. Figure 5(b) shows the proposed CSRR geometry with its dimensions. The CSRR geometry contains two circular rings.

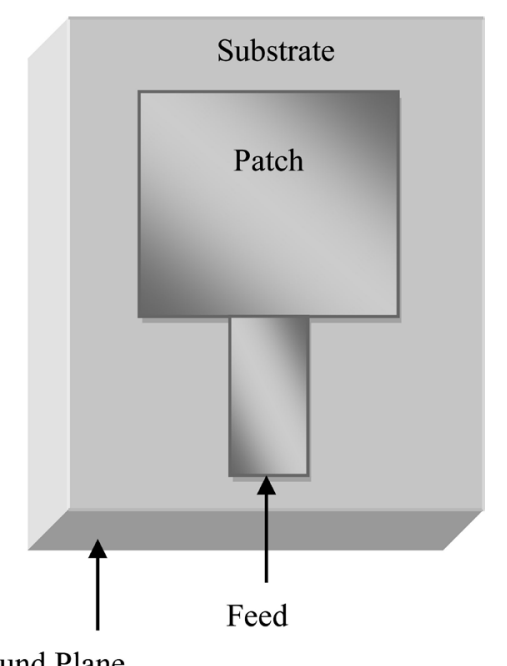

Ground Plane

Figure 4. Simple microstrip antenna geometry. 


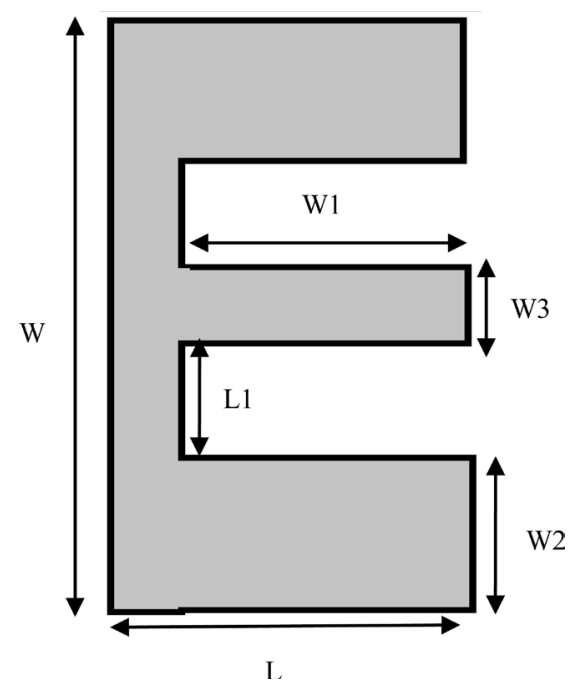

(a)

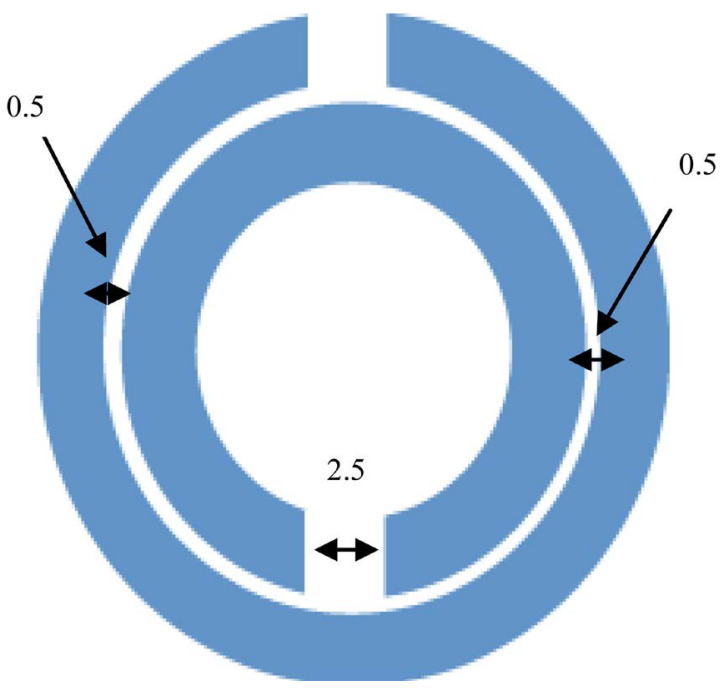

(b)

Calculate the corresponding length, width and other dimensions of the patch antenna using the design equations.

$\checkmark$

Calculate the appropriate coordinate values for all the sides of patch antenna.

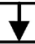

Enter the respective coordinates into the new workspace created in software.

\section{$\checkmark$}

Choose and give the proper feed, which supplies the RF power. Here simple microstrip-line feed has been used in the design.

\section{$\downarrow$}

Edit the substrate and other design parameters from the editor window and follow the simulation steps.

\section{$\downarrow$}

Change the port positions and repeat the simulation. Note the corresponding changes for every change.

\section{$\checkmark$}

Validate the corresponding results.

(c)

Figure 5. (a) Proposed microstrip antenna geometry; (b) Proposed CSRR geometry; (c) Flow graph of design procedure.

Table 1. Proposed antenna dimensions.

\begin{tabular}{cc}
\hline Parameters & Dimensions in mm \\
\hline W & 44 \\
L & 91 \\
W1 & 31 \\
W2 & 24 \\
W3 & 13 \\
L1 & 15 \\
\hline
\end{tabular}




\subsection{Design Procedure (Simulation)}

The design and analysis of the antenna is achieved through this software by using the design procedure in Figure 5(c).

\section{Results and Discussion}

The major elements of the proposed design are E-shape patch and Circular Complementary Split Ring Resonator (C-CSRR). Figures 6(a)-(c) show the designed simulation model for the cognitive radio applications which contains: Proposed Patch Antenna Design-Front, Back and overall view. To investigate the antenna by its parameters such as return loss, radiation pattern, Power radiated efficiency, gain and directivity.

\subsection{Return Loss}

The return loss is a measure of reflected power due to mismatching in the transmission line analogy. It is denoted as $S_{11}$ with the unit of dB. Figure 7(a) \& Figure 7(b) show the result for the return loss of proposed antenna system for with and without ground plane. Almost $80 \%$ of frequency ranges are covered between $2 \mathrm{GHz}$ to $5 \mathrm{GHz}$. And it is seen that, the antenna is operated in wideband characteristics. So it can easily be integrated into cognitive radio communication systems. For with ground plane: the return loss is about $-10 \mathrm{~dB}$ for $80 \%$ bands and reaches up to $-32 \mathrm{~dB}$ for frequencies of $2.4 \mathrm{GHz}$ and $2.9 \mathrm{GHz}$. And for without ground plane: the return loss is $-10 \mathrm{~dB}$ for $60 \%$ bands and reaches maximum of $-22 \mathrm{~dB}$ for $2.6 \mathrm{GHz}$. Ground plane is a field reflector, the size and plane provides larger effect on the antenna radiation characteristics and determining its resonance frequency, radiation pattern and other parameters. It shows that, the E-shape geometry is better choice for CR networks.

\subsection{Radiation Pattern}

The radiation pattern provides how the antenna radiates the transmitting power with respect to direction. The users may be located anywhere, so the antenna should cover all the directions from $0^{\circ}$ to $360^{\circ}$. Figure 8 shows the radiation pattern for proposed patch design. The red color from the figure shows the maximum radiation intensity to the user and the green indicates the above maximum level, green indicates the low level radiated power.

\subsection{Gain}

The ability of antenna can be measured through the antenna gain which is a ratio of radiated power to input power. Obtained gain is about $4 \mathrm{dBi}$ for all designed frequency band is shown in Figure 9. The graph has been plotted between Gain ( $\mathrm{dBi}$ ) and the Frequency (GHz).

\subsection{Directivity}

Directivity is a measure of directive gain at a particular direction. Obtained directivity is above $4.5 \mathrm{dBi}$ for all

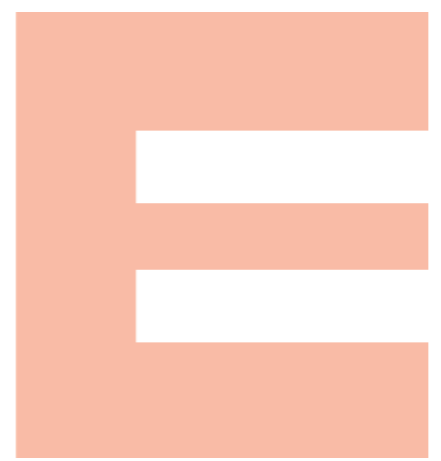

(a)

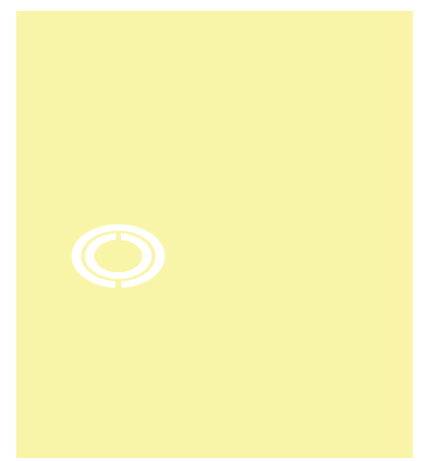

(b)

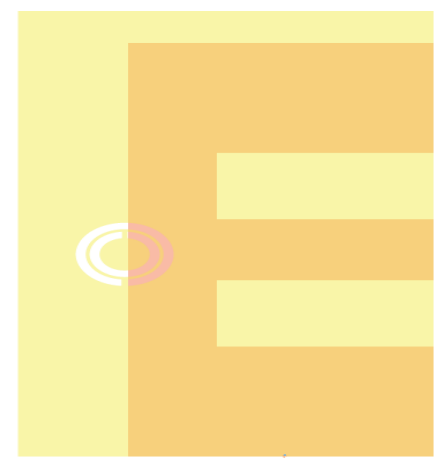

(c)

Figure 6. (a) Proposed patch antenna design—front; (b) Proposed patch antenna design—back; (c) Proposed patch antenna design-full view. 


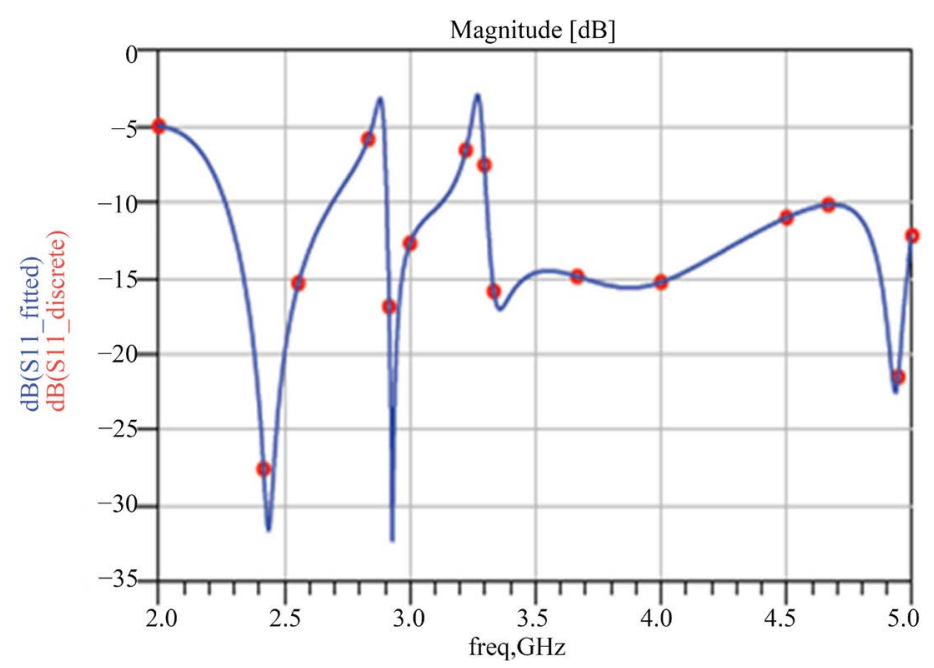

(a)

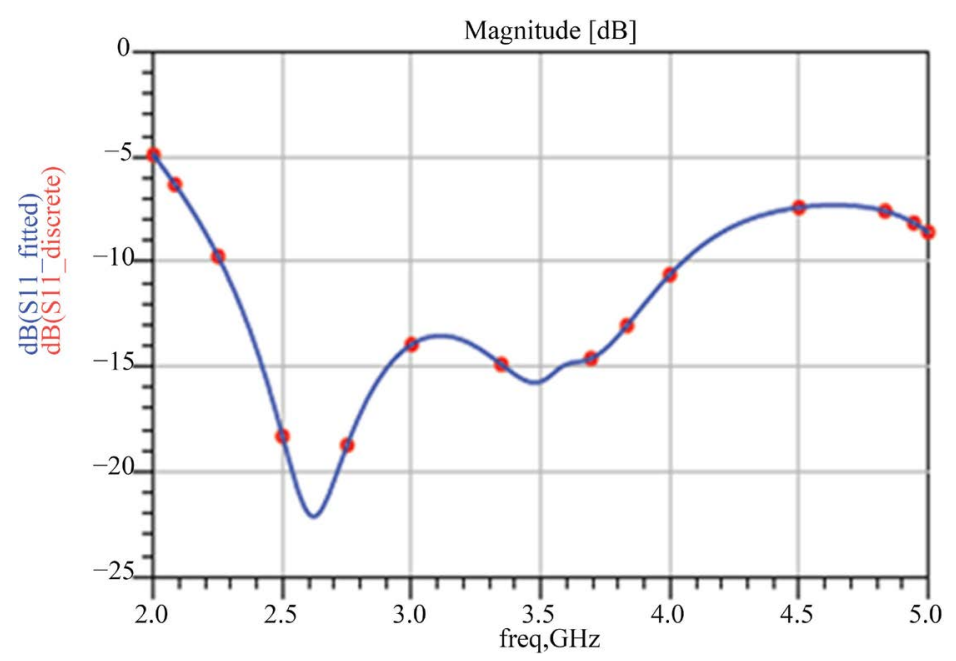

(b)

Figure 7. (a) Return loss ( $\mathrm{S}_{11}$ vs frequency) — with ground plane; (b) Return loss ( $\mathrm{S}_{11}$ vs frequency)—without ground plane.

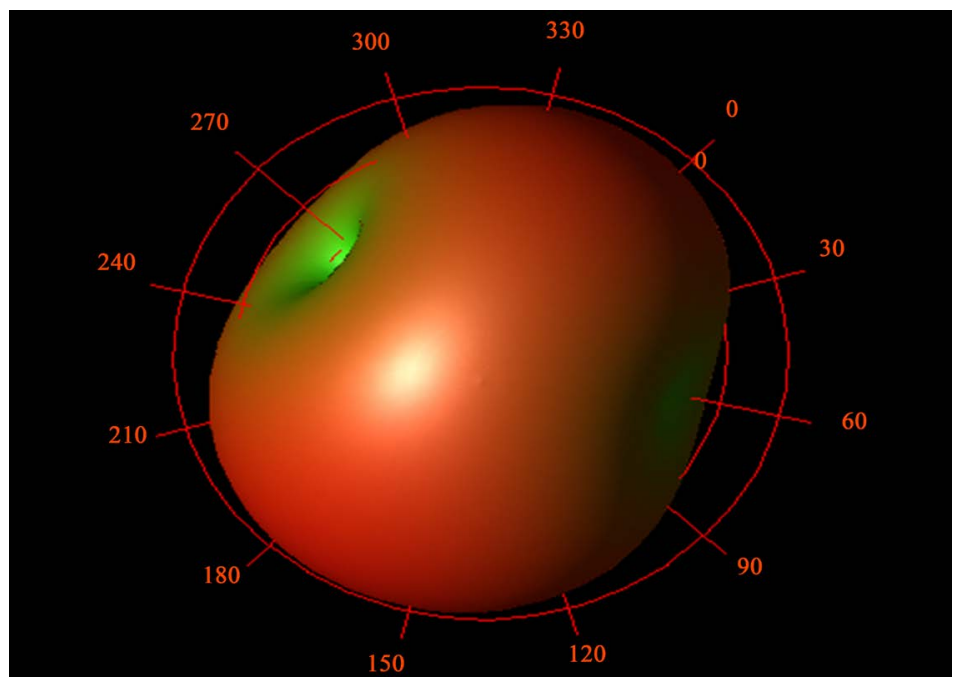

Figure 8. Radiation pattern. 


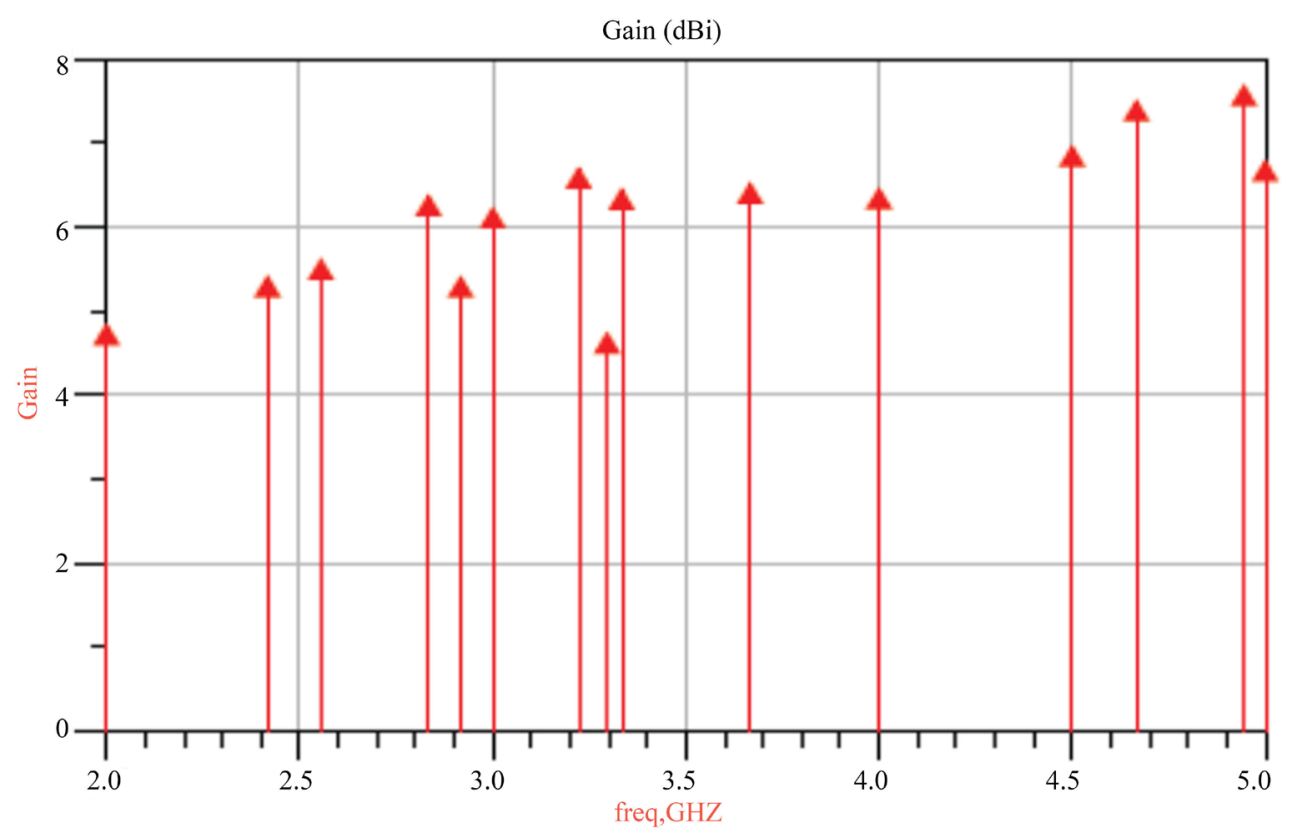

Figure 9. Gain for antenna with ground.

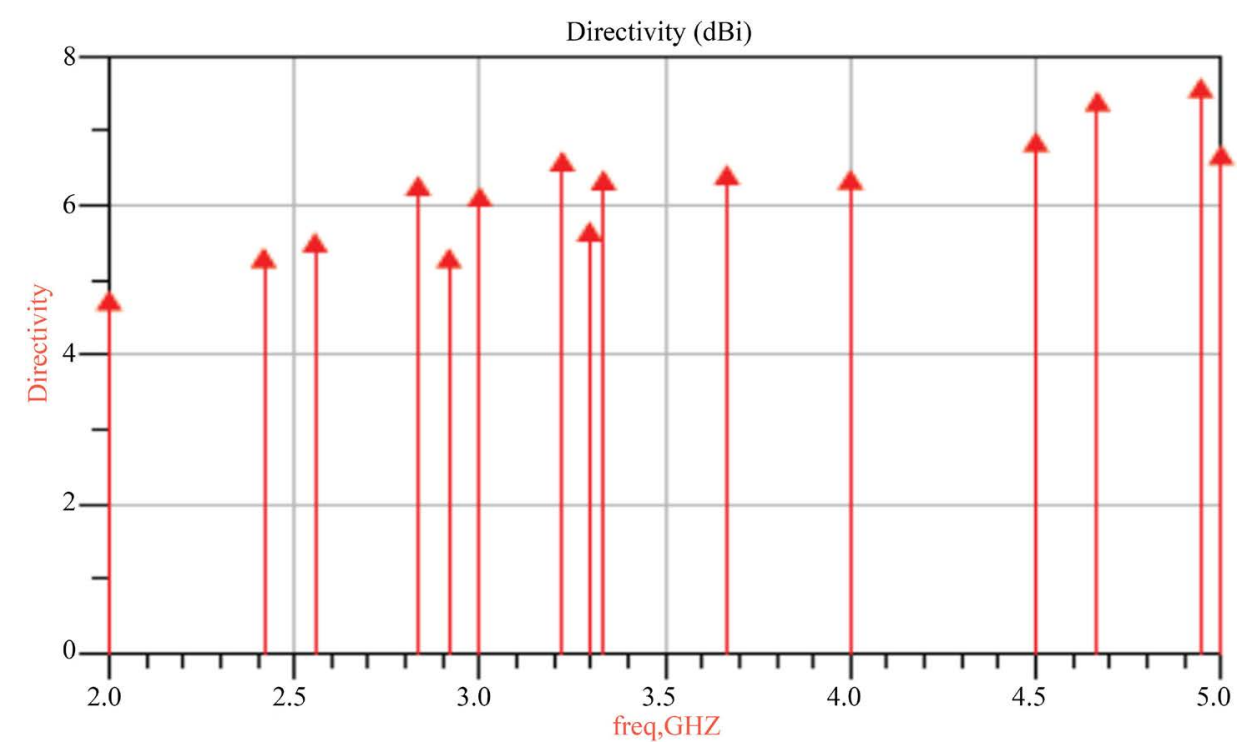

Figure 10. Directivity for antenna with ground.

designed frequency band is shown in Figure 10. The entire result shows that the proposed antenna design is best solution for cognitive radio networks. The investigated antenna parameters such as return loss, radiation pattern, gain and directivity are exhibits excellent performance between the frequencies of about $2.0 \mathrm{GHz}$ to $5.0 \mathrm{GHz}$.

\subsection{Efficiency and Radiated Power}

The efficiency of a patch antenna tells the power delivered to the antenna and the power radiated within the antenna. A high efficiency antenna has most of the power there at the antenna's input radiated away. A low efficiency antenna has most of the power absorbed due to impedance mismatch. For the proposed work, the antenna provides better efficiencies from $78 \%$ to $100 \%$ for the frequencies between 2 to $5 \mathrm{GHz}$. It shows that, all the power has been radiated properly as shown in Figure 11. And the antenna radiated power is shown in Figure 12 which provides the details for amount of power radiated from the antenna. 


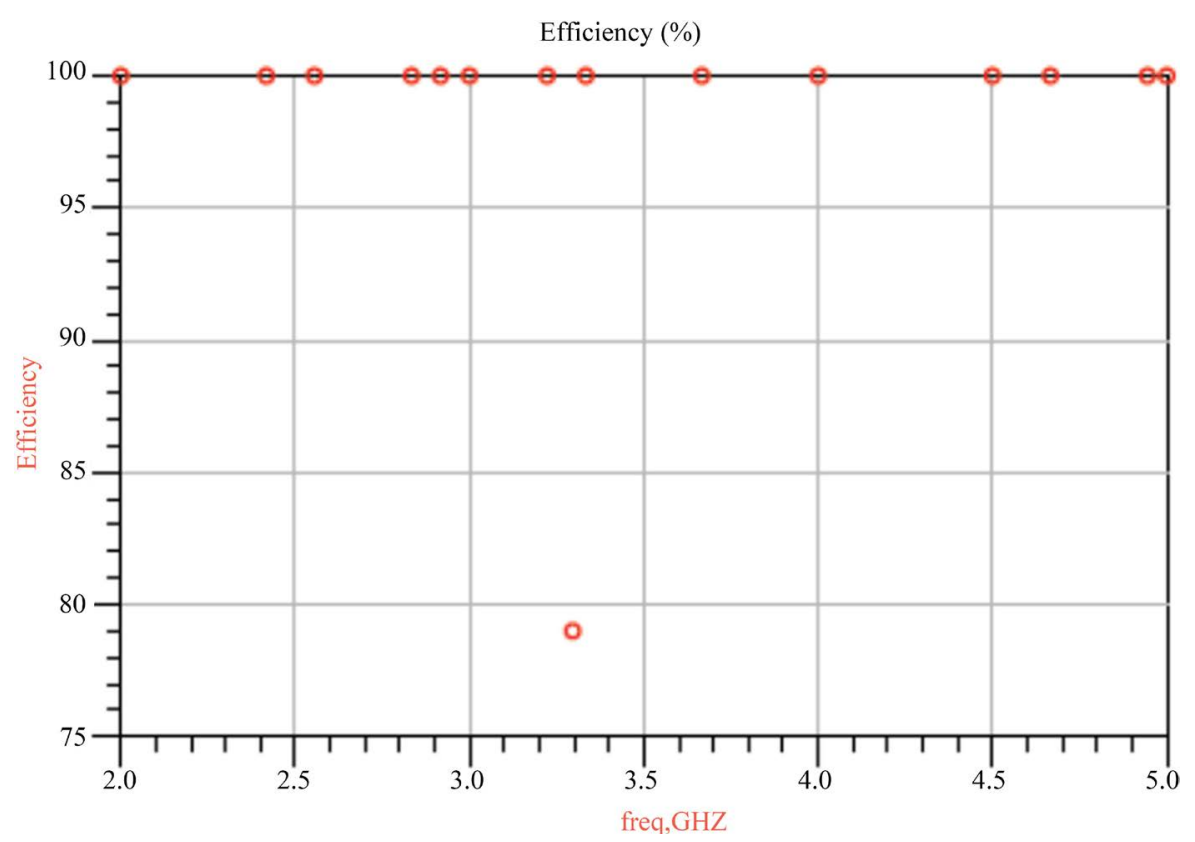

Figure 11. Antenna efficiency for with ground.

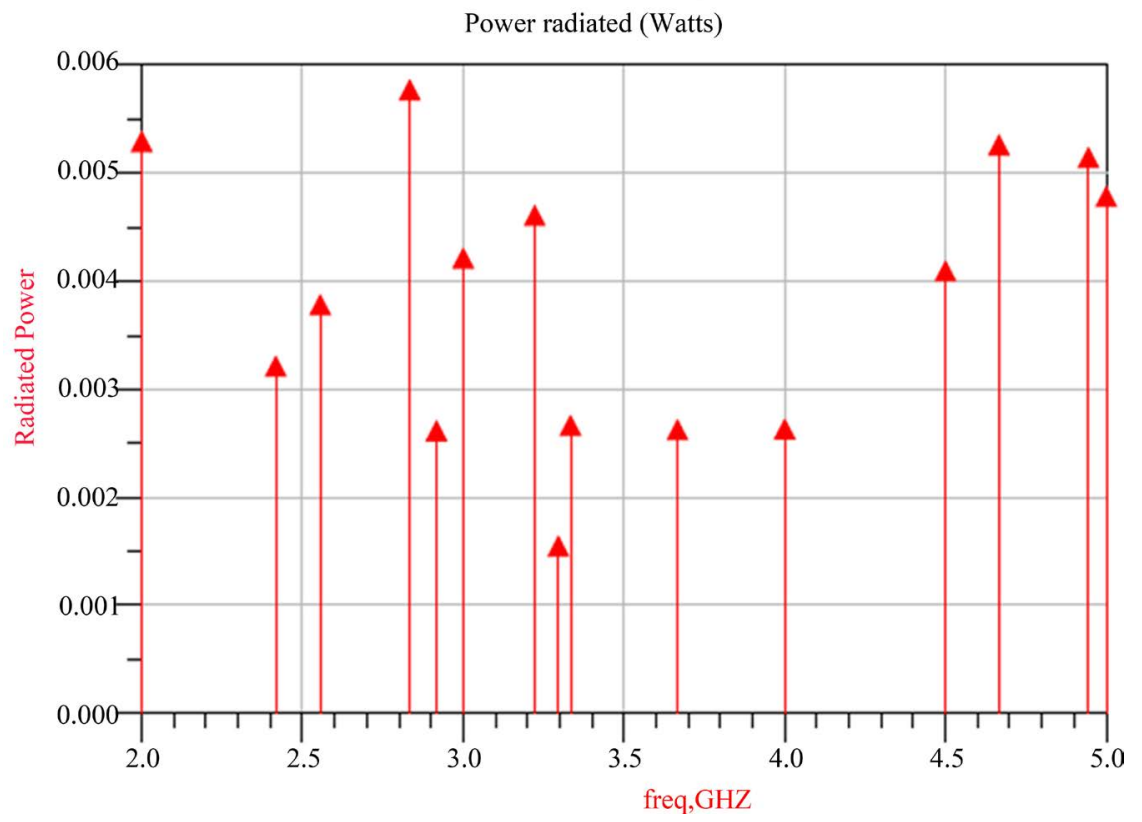

Figure 12. Antenna radiated power for with ground.

\subsection{Current Distribution}

Figure 13 shows that the current distribution of the antenna. The red regions in the figure indicating the high current distribution. This figure shows how well the current is distributed over the proposed antenna. From the plot it can be inferred that the proposed antenna is showing very good amount of current distribution over the antenna surface.

\section{Conclusion}

In this research work, a metamaterial inspired patch antenna is designed for the application of a cognitive radio 


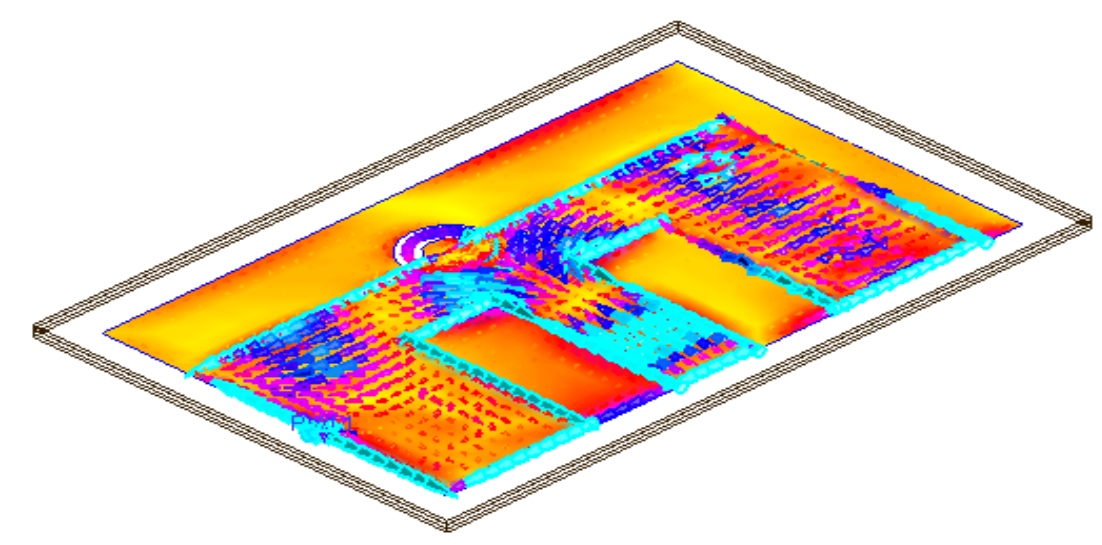

Figure 13. Current distribution-antenna with ground.

CR) communication system. A superior performance is obtained through this proposed antenna configuration. The proposed design system consists of E-shape patch with complementary split ring resonator. In order to achieve better size miniaturization, the CSRR is placed at the bottom of metallic sheet. Here a new compact design has been introduced to achieve highly miniaturized microstrip patch antenna for cognitive radio applications. Key feature of the proposed patch design is the wide bandwidth with very low reflection coefficient and $80 \%$ frequencies are covered between $2.0 \mathrm{GHz}$ to $5.0 \mathrm{GHz}$. It can be seen that the work demonstrated in this paper is mainly focused on minimizing the E-shape patch antenna. The geometrical shape can be also extended to other applications. The primary result shows that proposed miniaturization technique may be useful for developing microstrip antennas with wide or multi band performance.

\section{References}

[1] Rajagopalan, H. and Kovitz, J.M. (2014) MEMS Reconfigurable Optimized E-Shaped Patch Antenna Design for Cognitive Radio. IEEE Transactions on Antennas and Propagation, 62, 1056-1064. http://dx.doi.org/10.1109/TAP.2013.2292531

[2] Al-Husseini, M., Kabalan, K.Y., El-Hajj, A. and Christodoulou, C.G. (2013) Reconfigurable Microstrip Antennas for Cognitive Radio. InTechOpen Source, 2013, 338-362.

[3] Abutarboush, H.F., Nilavalan, R., Cheung, S.W., Nasr, K.M., Peter, T., Budimir, D. and Al-Raweshidy, H. (2012) A Reconfigurable Wideband and Multiband Antenna Using Dualpatch Elements for Compact Wireless Devices. IEEE Transactions on Antennas and Propagation, 60, 36-43.

[4] Ouedraogo, R.O., Rothwell, E.J., Diaz, A.R., Fuchi, K. and Temme, A. (2012) Miniaturization of Patch Antennas Using a Metamaterial-Inspired Technique. IEEE Transactions on Antennas and Propagation, 60, 2175-2182.

[5] Ouedraogo, R.O. and Rothwell, E.J. (2010) Metamaterial-Inspired Patch Antenna Miniaturization Technique. IEEE Antennas and Propagation Society International Symposium, Toronto, 11-17 July 2010, 1-4.

[6] Ouedraogo, R.O., Rothwell, E.J., Diaz, A.R., Chen, S.Y., Temme, A. and Fuchi, K. (2010) In Situ Optimization of Meta Material-Inspired Loop Antennas. IEEE Antennas and Wireless Propagation Letters, 9, 75-78. http://dx.doi.org/10.1109/LAWP.2010.2043409

[7] Lee, Y., Tse, S., Hao, Y. and Parani, C.G. (2007) A Compact Microstrip Antenna with Improved Bandwidth Using Complementary Split Ring Resonator (CSRR) Loading. IEEE Antennas and Propagation Society International Symposium, Honolulu, 9-15 June 2007, 5431-3534.

[8] Abu Tarboush, H.F., Khan, S., Nilavalan, R., Al-Raweshidy, H.S. and Budimir, D. (2009) Reconfigurable Wideband Patch Antenna for Cognitive Radio. Loughborough Antennas \& Propagation Conference, Loughborough, 16-17 November 2009, 141-144.

[9] Li, M., Lu, M. and Cui, T.J. (2008) Novel Miniaturized Dual Band Antenna Design Using Complementary Metamaterial. International Workshop on Metamaterials, Nanjing, 9-12 November 2008, 374-376.

[10] Hall, P.S., Gardner, P., Kelly, J., Ebrahimi, E., Hamid, M.R. and Ghanem, F. (2008) Antenna Challenges in Cognitive Radio. Proc. ISAP 08, Taiwan, October 2008.

[11] Balanis, C. (1997) Antenna Theory. 2nd Edition, Wiley, Hoboken, Chapter 14.

[12] Haykin, S. (2005) Cognitive Radio: Brain-Empowered Wireless Communications. IEEE Journal on Selected Areas in Communications, 23, 201-220. 